retirement adjustment, but that these effects are largely explained through the role of extraversion and neuroticism for perceptions of self, individual control, and social relations in retirement.

\section{UNDERSTANDING THE ROLES OF PATIENT SYMPTOMS AND SUBJECTIVE APPRAISALS IN WELL- BEING AMONG BREAST CANCER PATIENTS}

A. Badana ${ }^{1}$, V. Marino ${ }^{1}$, M. Templeman ${ }^{1}$, C. Tofthagen ${ }^{2}$, S. McMillan², B. Small ${ }^{1}$, W. Haley ${ }^{1}$, 1. School of Aging Studies, University of South Florida, Tampa, FL, USA, 2. College of Nursing, University of South Florida, Tampa, FL, USA

We examined the roles of both patient symptoms, and subjective appraisals of stress (self-efficacy, symptom barriers, symptom distress) in understanding well-being (anxiety, depression, cancer specific quality of life, mental health quality of life, and physical health quality of life) in breast cancer patients. We examined data from 104 breast cancer patients. Using a stress process model, we hypothesized that while high levels of patient symptoms would be associated with poorer patient well-being, these effects would be mediated by subjective appraisals including patient self-efficacy, perceived symptom barriers, and symptom distress. As expected, higher levels of patient symptoms were associated with poorer well-being on all five indicators. Subjective appraisals of stress added significantly to predictors of well-being, and were mediators of this relationship across all five outcomes. While patient symptoms are important predictors of patient well-being, subjective appraisals of the stressfulness of symptoms, and of patients' self-efficacy in managing symptoms, are also key factors. The findings suggest the utility of a stress process model in understanding well-being in breast cancer patients, and point to the potential value of targeting patient appraisals as well as symptoms to improve psychological well-being and quality of life.

\section{VOLUNTEERISM IN OLDER ADULTHOOD: UNDERSTANDING THE FACTORS ASSOCIATED WITH WELL-BEING}

\section{K. Graham, G. Fisher, D. Davalos, Colorado State} University

Approximately 270,000 seniors (55+) in the U.S. engage in volunteering through Senior Corps' programs (Corporation for National Community and Service, 2016). Volunteering in older adulthood has been consistently connected with psychological, physical, and cognitive well-being (Carr, 2018), with a moderate level of volunteering considered optimal (Windsor, Anstey, and Rodgers, 2008). The relationship between perceived level of demands within a volunteering position (e.g., physical, social, and cognitive demands) and well-being has not been explored. The sample consisted of 110 senior volunteers in Colorado (Mage=71 years). The median number of volunteer hours over the past 12 months was 100 hours $(M=157, S D=162)$. We investigated how hours of volunteering and characteristics of volunteer work relate to five dimensions of subjective well-being (e.g., positive emotion, engagement, relationships, meaning, and accomplishment; Butler \& Kern, 2016), and overall health status. Number of hours spent volunteering was positively related to one of the well-being variables, meaning $(\mathrm{r}=.21$, $\mathrm{p}=.03$ ). Volunteers who described their work as being more socially demanding reported being in worse health $(\mathrm{r}=-.28$, $\mathrm{p}=.07)$. Volunteers who described their work as being more physically demanding indicated that they believed others were better off as a result of their work $(r=.45, p=.003)$. The results of the present study support the positive impact of volunteering on well-being. Specifically, greater volunteering is related to a sense of purpose in life or sense that life matters. These results also indicate that exploring the impact of volunteer work characteristics may be a direction for future research.

\section{WHAT WILL MY LIFE BE LIKE AT AGE 70?: PERSPECTIVES OF UNDERGRADUATE STUDENTS IN AN AGING COURSE}

\section{S. Lowey, State University of New York - The College at} Brockport-

The affective domain of learning, according to Bloom's Taxonomy, is an essential component in the professional development of students' pursuing a healthcare career. Teaching strategies that stimulate an emotional response can impact students' attitudes, values and beliefs towards the subject matter. The purpose of this qualitative descriptive study was to examine the perspectives of undergraduate nursing students about an assignment that prompted a visualization of their life as an older adult and to critically reflect on how they would incorporate those perspectives when caring for patients. Narrative data was extracted from 143 undergraduate students' essays about perceptions of their life at age 70 . Reflections about both positive and negative features were included. The majority of students identified the assignment in a positive light and as a real "eye opener." Many reported that they felt fortunate that this was only an assignment and though they "still had lots of time left," perceived the lives of their older adult patients in a different light. Several students consulted with a grandparent or neighbor while writing the paper, which led to a mutually satisfying connection with an older adult. Students were most fearful about loss of functional status, being too ill to enjoy activities and the death of loved ones. Healthcare students often lack the ability to see patients beyond their current health status because educational programs largely foster development in the cognitive domain. Utilizing strategies targeting the affective domain can help healthcare students reconsider their values and beliefs towards the older population.

\section{SESSION 1215 (POSTER)}

\section{SEX AND GENDER}

BARRIERS TO SEXUAL PLEASURE: SEXUAL CHARACTERISTIC DIFFERENCES THROUGHOUT THE DEVELOPMENTAL STAGES OF ADULTHOOD

R. Reinhardt, Z. Moore, R. Bennett, A. Lapham, A. Stripling, Nova Southeastern University

Throughout the developmental stages of adulthood changes in sexual functioning have been noted. Despite 